\title{
Evaluation of the anti-Toxoplasma gondii Activity of Hederagenin in vitro and in vivo
}

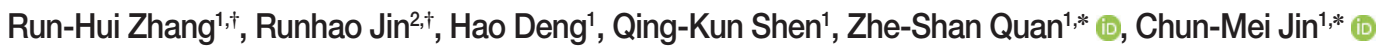 \\ ${ }^{1}$ Key Laboratory of Natural Medicines of the Changbai Mountain, Ministry of Education, Yanbian University, Yanji 133002, China; \\ ${ }^{2}$ School of nursing Yanbian University, Yanji 133002, China
}

\begin{abstract}
Toxoplasma gondii infection is widespread worldwide, not only posing a serious threat to human food safety and animal husbandry, but also endangering human health. The selectivity index was employed to measure anti-T. gondii activity. Hederagenin (HE) exhibited potent anti-T. gondii activity and low cytotoxicity. For this reason, HE was selected for in vivo experiments. HE showed $64.8 \% \pm 13.1 \%$ inhibition for peritoneal tachyzoites in mice, higher than spiramycin $56.8 \% \pm 6.0 \%$. Biochemical parameters such as alanine aminotransferase, aspartate aminotransferase, glutathione, and malondialdehyde, illustrated that $\mathrm{HE}$ was a good inhibitor of $T$. gondii in vivo. This compound was also effective in relieving T. gondii-induced liver damage. Collectively, it was demonstrated that HE had potential as an anti-T. gondii agent.
\end{abstract}

Key words: Toxoplasma gondii, hederagenin, inhibition, in vitro, in vivo

Toxoplasmosis is caused by T. gondii, which is a globally distributed parasite. This parasite infects many nucleated cells of mammals and humans and an estimated 2 billion people worldwide [1]. The disease is normally asymptomatic in hosts with normal immune function and no treatment is required. However, parasites can cause more serious and potentially lifethreatening harm to people with immune deficiencies [2].

Clinically, a combination of sulfa drugs and dihydrofolate reductase inhibitors have been used to successfully treat and prevent various diseases caused by T. gondii [3]. This has played an important role in human anti-toxoplasmosis but these interventions can cause adverse reactions, including bone marrow suppression, hypersensitivity, hematologic toxicity and rashes [4]. These drawbacks highlight the need for drugs with anti-T. gondii activity that function with high efficiency, low toxicity and fewer side effects.

Natural products are considered promising reservoirs for drug discovery and are vital in drug development programs [57]. Hederagenin (HE) is a pentacyclic oleane-type triterpenoid found in large quantities in the pericarps of fruits of Sapindus saponaria (Sapindaceae) [8]. Several biological activities have

- Received 6 September 2020, revised 11 April 2021, accepted 15 April 2021.

*Corresponding authors (zsquan@ybu.edu.cn; cmjin@ybu.edu.cn)

†These authors contributed equally to this work.

(c) 2021, Korean Society for Parasitology and Tropical Medicine

This is an Open Access article distributed under the terms of the Creative Commons Attribution Non-Commercial License (https://creativecommons.org/licenses/by-nc/4.0) which permits unrestricted non-commercial use, distribution, and reproduction in any

medium, provided the original work is properly cited. been reported for $\mathrm{HE}$, including antifungal [9], anti-leishmanial [10]. Due to such reports and our continued interest in the search for bioactive compounds from the natural products, we recently started to investigate the potential of $\mathrm{HE}$ as a source of new anti-T. gondii drugs. HE exhibited low cytotoxicity and high selectivity indices in in vitro studies and was selected for analysis in vivo. The research aimed to lay the foundation for elucidating mechanism study anti-T. gondii of compound HE.

Dulbecco's Modifified Eagle Medium (DMEM), PenicillinStreptomycin solution, Trypsin-EDTA, and Phosphate Buffered Saline (PBS) for cell culture were obtained from Biological Industries (Beijing, China). Fetal bovine serum (FBS) for cell culture was purchased from Gemini (California USA). Spiramycin (FW 843.05) was purchased from Aladdin Industrial Inc. (Shanghai, China). HE was obtained from Nanjing Spring\& Autumn Biotech Co. Ltd (purity > 98\%). Each compound was dissolved in dimethyl sulfoxide (DMSO, Solarbio, Beijing, China) and diluted with DMEM to different concentrations, with the final DMSO concentration at less than $1 \%(\mathrm{v} / \mathrm{v})$.

HeLa cells were cultured in DMEM, supplemented with 100 units/ml Penicillin and $100 \mu \mathrm{g} / \mathrm{ml}$ Streptomycin and 10\% heat-inactivated $\mathrm{FBS}$ and maintained at $37^{\circ} \mathrm{C}$ and $5 \% \mathrm{CO}_{2}$. Cells were purchased from American Type Culture Collection (Manassas, Virginia, USA). Tachyzoites used in our study were from the virulent RH strain of $T$. gondii and maintained by serial intraperitoneal passage in KM female mice. KM female mice were purchased from Experiment Center, Yanbian Uni- 
versity. All experimental procedures were conducted in conformity with institutional guidelines for the care and use of laboratory animals in Yianbian University, Jilin, China (experiment alanimal ethics batch number IACUC-20170105039), and conformed to the National Institutes of Health Guide for Care and Use of Laboratory Animals (Number of license SCXK 2011-0007). All mice were kept in a central animal care facility with free access to water and rodent food during the experiment.

HeLa cells were seeded onto the 96-well plates $\left(3 \times 10^{3}\right.$ cells per well) for $24 \mathrm{hr}$ for obtaining the full monolayer, and then the host cells were infected with T. gondii (parasites: cells $=5: 1$ ) in complete medium. After $24 \mathrm{hr}$, cells were washed to remove any extra parasites and then incubated with different concentrations (1-1,000 $\mu \mathrm{M})$ of compounds served. Spiramycin was used as positive control. After $24 \mathrm{hr}$ of incubation, $10 \mu \mathrm{l}$ of 5 $\mathrm{mg} / \mathrm{ml}$ MTT solution was added to each well. Plates were then incubated for a further $4 \mathrm{hr}$. IC $\mathrm{5}_{50}$ in HeLa cells, IC $\mathrm{I}_{50}$ in infected HeLa cells and selectivity index were calculated by Excel software. Selectivity index was a measure of specific resistance to Toxoplasma. Calculated using the formula shown in Table 1.

Female mice were randomly divided into 4 groups and then intraperitoneally injected with $2 \times 10^{3}$ tachyzoites of the T. gondii $\mathrm{RH}$ strain. After $4 \mathrm{hr}$ of infection, mice were orally treated or not with different drugs: $0.2 \mathrm{ml}$ normal saline (normal group and toxo control group), $100 \mathrm{mg} / \mathrm{kg}$ spiramycin (spi group), $100 \mathrm{mg} / \mathrm{kg}$ Hederagenin (HE group) according to the mice weight, respectively, once a day for 4 days. At the last day, eye blood samples were collected after anesthesia to separate the serum, and then mice were sacrificed by cervical dislocation. After that, the number of tachyzoites in the abdominal cavity of the mice was counted under the light microscope and the inhibition rate of the parasites was calculated. Then the liver and spleen were dissected. The determination of liver and spleen index, serum (Alanine aminotransfease) ALT, (Aspartate

Table 1. Inhibition and cytotoxicity of two compounds on T. gondii-infected HeLa cells in vitro

\begin{tabular}{lccc}
\hline Compound & $\mathrm{CC}_{50}(\mu \mathrm{m})^{\mathrm{a}}$ & $\mathrm{EC}_{50}(\mu \mathrm{m})^{\mathrm{b}}$ & $\mathrm{Sl}^{\mathrm{c}}$ \\
\hline Hederagenin & $633.1 \pm 0.9$ & $547.8 \pm 8.2$ & 1.16 \\
Spiramycin & $189.0 \pm 1.5$ & $262.2 \pm 7.5$ & 0.72 \\
\hline
\end{tabular}

${ }^{\mathrm{a}} \mathrm{C}_{50}$ in HeLa Cell =Median toxicity concentration, a measure of cytotoxicity against host cells.

${ }^{b} \mathrm{C}_{50}$ in $\mathrm{T}$. gondii infected HeLa cells = Median inhibitory concentration, a measure of tachyzoite inhibition.

'Selectivity index calculated by $\mathrm{CC}_{50} / \mathrm{EC}_{50}$. aminotransferase) AST, and liver homogenate (Glutathione) GSH and (Malondialdehyde) MDA were determined [13]. Determination of ALT and AST method: The substrate reaction of ALT or AST and serum was carried out under incubation at $37^{\circ} \mathrm{C}$ for $30 \mathrm{~min}$, then added 2,4-dinitrophenylhydrazine (2,4$\mathrm{DNPH}$ ) and held for $20 \mathrm{~min}$. Finally, $\mathrm{NaOH}$ was added and allowed to react for $5 \mathrm{~min}$. The absorbance at $505 \mathrm{~nm}$ was measured. Determination of GSH method: The liver homogenate was mixed with half volume trichloroacetic acid $(20 \%$, $\mathrm{w} / \mathrm{v}$ ) and centrifuged at 4,000 rpm for $10 \mathrm{~min}$. Then, phosphate buffer (phosphate $0.3 \mathrm{~mol} / \mathrm{L}, \mathrm{pH} 7.5$ ) and 5,5-dithiobis-(2nitrobenzoic acid) $(0.04 \%, w / v)$ were added to the separated supernatant and mixed thoroughly. After $5 \mathrm{~min}$ at room temperature, the absorbance was measured at $412 \mathrm{~nm}$. Determination of MDA method: The liver homogenate supernatant was mixed with thiobarbituric acid $(0.5 \%, \mathrm{w} / \mathrm{v})$ and heated in boiling water bath for $1 \mathrm{hr}$, then cooled quickly and centrifuged at 6,000 rpm for $10 \mathrm{~min}$, the absorbance of pink colored supernatant was measured at $532 \mathrm{~nm}$. Tetraethoxypropane replaced the liver homogenate in the standard sample. Another 18 mice were randomly divided into infected untreated group, infected with $100 \mathrm{mg} / \mathrm{kg}$ spiramycin- treated group (spi) and infected with HE-treated group, 6 in each group. Four hours after the infection, the mice were orally gavage as described above and administered once a day for several consecutive days to observe the survival rate of the mice. All data were expressed as mean \pm standard deviation of triplicate measurements.

Statistical analyses were performed using GraphPad Prism 5.0 (GraphPad Software Inc., San Diego, California, USA). A value of $P<0.05$ was considered statistically significant.

In this study, HE was selected to evaluate their anti-T. gondii activity in vitro. When the SI level was higher than that obtained for spiramycin, the toxicity of the compound to the host cells (HeLa cells) was lower than spiramycin, and the compound reduced the T. gondii-induced infection of the host cells; then the compound was considered to have improved anti-T. gondii activity. The cell viability of $T$. gondii-infected HeLa cells was compared to uninfected HeLa cells and was expressed as a percentage change from the control value. The selectivity index (SI) is generally reflected the efficacy of a compound against T. gondii and toxicity for host cells, which was calculated using the formula: the ratio of the median toxicity concentration ( $\mathrm{CC}_{50}$, IC $\mathrm{C}_{50}$ in HeLa Cell) value for host cells not infected with T. gondii to the median inhibitory concentration 
(EC ${ }_{50}, \mathrm{IC}_{50}$ in $T$. gondii infected HeLa cells) for $\mathrm{T}$. gondii cultivated in host cells ( $\mathrm{SI}=\mathrm{CC}_{50} / \mathrm{EC}_{50}$ ) [11].

The results are summarized in Table 1. HE exhibited stronger SI than the clinical toxoplasmosis medication spiramycin ( $\mathrm{SI}=0.72$ ). The compound HE contains 2 hydroxyl groups and one carboxyl group, and SI values greater than spiramycin. It is hypothesized that the hydroxyl groups interact with the receptor protein by hydrogen bonding thus resulting in their

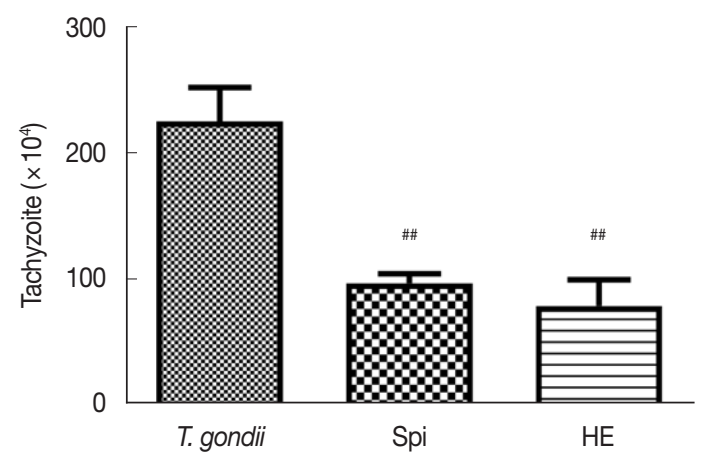

Fig. 1. Effect of compounds on the number of tachyzoites in mice, $n=6,{ }^{\# \#} P<0.01$ compared with toxo group.

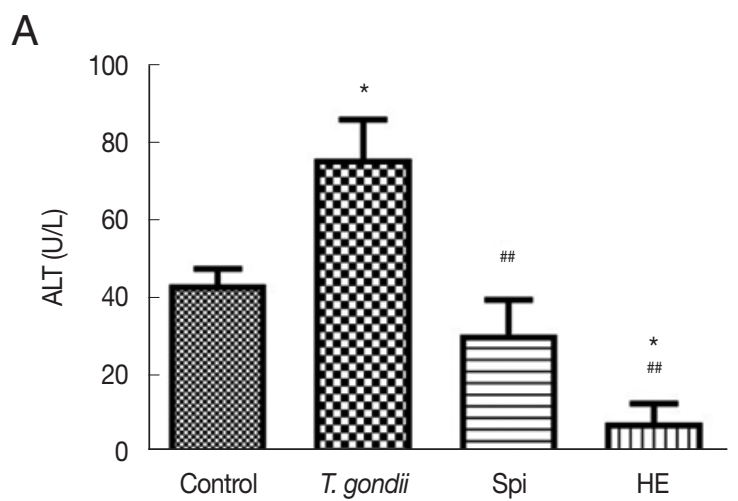

B

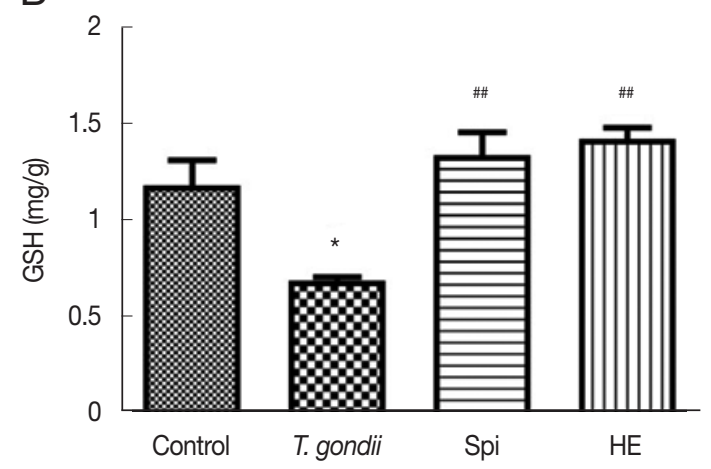

enhanced biological activity. HE had a high SI and also showed the lowest toxicity to HeLa cells. For this reason, HE was selected for further analysis in in vivo studies.

To determine whether HE exhibited anti-T. gondii activity in vivo, we infected female KM mice with a T. gondii RH strain to construct an acute T. gondii infection model. We administered HE and spiramycin by gavaging and then evaluated the number of $T$. gondii in the abdominal cavities of mice by counting [14]. The number of tachyzoites in the ascitic fluid of mice treated with $100 \mathrm{mg} / \mathrm{kg}$ spiramycin and $100 \mathrm{mg} / \mathrm{kg} \mathrm{HE}$ decreased compared to the control mice; the inhibitory rates were $56.8 \% \pm 6.0 \%$ and $64.8 \% \pm 13.1 \%$, respectively (Fig. 1). These results indicate that HE inhibited the activity of tachyzoites in vivo, and at a rate close to spiramycin.

Serum levels of ALT and AST activity are sensitive indicators of hepatotoxicity. Elevated levels of these enzymes provided indices of the degree of liver damage (Fig. 2A). Compared to the levels of ALT and AST in the control group, the serum levels of ALT and AST were increased in mice infected with T. gondii. This indicates that acute T. gondii infection could result in
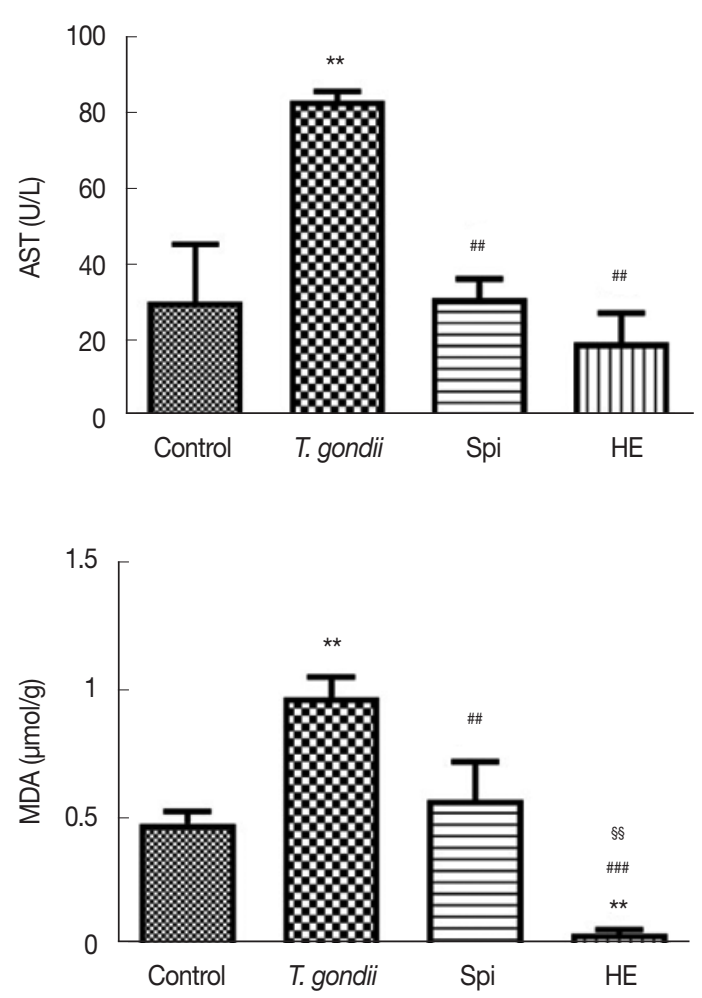

Fig. 2. (A) Effect of compounds on ALT and AST levels in T. gondii-infected KM mice, $n=6$. (B) Effect of compounds on GSH and MDA levels in T. gondii-infected KM mice, $n=6$. ${ }^{*} P<0.05$ compared with the normal group; ${ }^{* \star} P<0.01$ compared with the normal group; ${ }^{\# \# P} P 0.01$ compared with toxo group; \#\# $P<0.01$ compared with toxo group; $\$ \$ P<0.01$ compared with Spi group. 


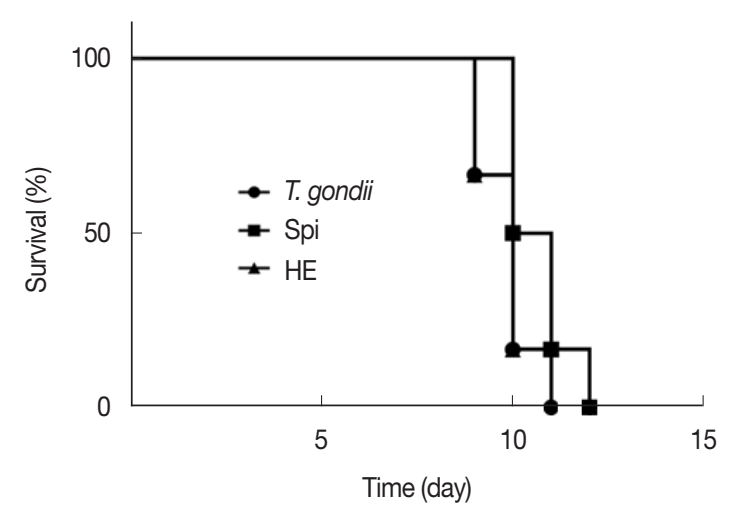

Fig. 3. Survival rates of inoculated mice with tachyzoites of $T$. gondii, $\mathrm{RH}$ strain and treated with compounds, compared with control group $(n=6)$.

liver damage. The levels of ALT and AST were significantly reduced in the HE-treated mice when compared to the levels of the same enzymes in T. gondii infected mice and the infected mice that had been treated with spiramycin $(P<0.05)$. These results indicate that HE could reduce the hepatotoxicity while targeting T. gondii.

MDA is the major degradation product of lipid peroxidation and can cause changes in the structure of hepatocytes, leading to their swelling and necrosis [18]. The level of MDA reflects the degree of damage to the liver cells from an alternative perspective [19]. GSH, the major non-protein thiol in humans and other mammals, can react with peroxides to exert anti-oxidative effects and to reduce liver damage [20]. Compared to the control group, the glutathione (GSH) content in the liver homogenate of the $T$. gondii infected mice was significantly reduced $(P<0.01)$. This indicated that an acute T. gondii infection caused a decrease in the anti-oxidant GSH, in mice (Fig. 2B). T. gondii infected mice that were treated with HE and spiramycin showed significantly elevated levels of GSH relative to the levels detected in the T. gondii infected mice.

The T. gondii infected mice exhibited higher levels of MDA compared to the control mice $(P<0.01)$. Treatment with spiramycin and HE resulted in a reduction in the levels of MDA. After treated with HE, there was a small amount of MDA when compared to the control group $(P<0.01)$. HE treatment resulted is a greater reduction of MDA than spiramycin treatment $(P<0.01)$. Studies have shown that a Toxoplasma infection can cause a reduction in the body's defense capacity. MDA may be elevated in the body to protect tissues from free radical damage [21]. The mechanism by which HE, an anti-oxidant, protects against a T. gondii infection may involve its anti-oxida- tive activity. This suggests that anti-oxidants may have potential in a therapeutic regimen for the treatment of $T$. gondii-related diseases [22].

After the administration of the infected mice, the length of their survival time can reflect the strength of the protective effect of the drug on the acutely infected mice with $T$. gondii. The longer the infected mice survive, the stronger the protective effect of the drug on the acutely infected mice. It can be seen from Fig. 3 that the mice in the toxo group and the HE group began to die on the 9th day, and the survival rate was $67 \%$. On the 10th day, the mice in the Spi group began to die with a survival rate of $50 \%$, while the survival rate of the mice in the toxo group and the HE group was 17\%; On the 11th day, all the mice in the toxo group died, while the survival rate of the mice in the HE group and the Spi group was 17\%. All mice died on the 12th day. These results show that both Spi and HE can control the pathological changes in the acutely infected mice to a certain extent, prolong the survival time of the mice, and have a certain protective effect on the acutely infected mice. From in vivo experimental data, HE did not show too ideal anti-T. gondii activity. The structure modification method can be used to make it an ideal anti-T. gondii drug. At the same time, a combination of drugs can be used to enhance the antiT. gondii activity of HE and reduce some side effects caused by HE.

In this study, we selected HE to study their anti-T. gondii activity in vitro. The conclusion is that HE exhibited superior activity compared to spiramycin, a drug used for the treatment of T. gondii infection. Simultaneously, HE was a good inhibitor of T. gondii in vivo and that it was effective in relieving the liver damage induced by $T$. gondii, and prolong the survival time of the mice to a certain extent. For this reason, HE has potential as an anti-T. gondii drug. Further studies are required to elucidate the mechanism of the action of $\mathrm{HE}$, as well as to develop drug delivery systems for patients.

\section{ACKNOWLEDGMENT}

This work was supported by the National Natural Science Foundation of China (No.81160409, 81960626).

\section{CONFLICT OF INTEREST}

No potential conflict of interest was reported by the authors. 


\section{REFERENCES}

1. Tenter AM, Heckeroth AR, Weiss LM. Toxoplasma gondii: From animals to humans. Int J Parasitol 2000; 30: 1217-1258. https:// doi.org/10.1016/s0020-7519(00)00124-7

2. Osunkalu VO, Akanmu SA, Ofomah NJ, Onyiaorah IV, Adediran AA, Akinde RO, Onwuezobe IA. Seroprevalence of Toxoplasma gondii igg antibody in hiv-infected patients at the lagos university teaching hospital. HIV/AIDS (Auckl) 2011; 3: 101-105. https://doi.org/10.2147/hiv.s15532

3. Martins-Duarte ÉS, de Souza W, Vommaro RC. Toxoplasma gondii: The effect of fluconazole combined with sulfadiazine and pyrimethamine against acute toxoplasmosis in murine model. Exp Parasitol 2013; 133: 294-299. https://doi.org/10.1016/j.exppara.2012.12.011

4. Mui EJ, Jacobus D, Milhous WK, Schiehser G, Hsu H, Roberts CW, Kirisits MJ, McLeod R. Triazine inhibits Toxoplasma gondii tachyzoites in vitro and in vivo. Antimicrob Agents Chemother 2005; 49: 3463-3467. https://doi.org/10.1128/aac.49.8.3463-3467.2005

5. Deng H, Huang X, Jin CM, Jin CM, Quan ZS. Synthesis, in vitro and in vivo biological evaluation of dihydroartemisinin derivatives with potential anti-Toxoplasma gondii agents. Bioorg Chem 2020; 94: 103467. https://doi.org/10.1016/j.bioorg.2019.103467

6. Luan T, Jin CM, Jin CM, Gong GH, Quan ZS. Synthesis and biological evaluation of ursolic acid derivatives bearing triazole moieties as potential anti-Toxoplasma gondii agents. J Enzyme Inhib Med Chem 2019; 34: 761-772. https://doi.org/10.1080/147 56366.2019.1584622

7. Shang FF, Jin L, Zhang HB, Piao LX, Quan ZS. Synthesis and antitoxoplasma activity in vitro of chrysin derivatives. Chin J Org Chem 2019; 39: 2574-2580 (in Chinese). https://doi.org/10.6023/cjoc 201901016

8. Rodríguez-Hernández D, Demuner AJ, Barbosa LCA, Csuk R, Heller L. Hederagenin as a triterpene template for the development of new antitumor compounds. Eur J Med Chem 2015; 105: 57-62. https://doi.org/10.1016/j.ejmech.2015.10.006

9. Saha S, Walia S, Kumar J, Parmar BS. Structure-biological activity relationships in triterpenic saponins: the relative activity of protobassic acid and its derivatives against plant pathogenic fungi. Pest Manage Sci 2010; 66: 825-831. https://doi.org/10.1002/ps. 1947

10. Rodríguez-Hernández D, Barbosa LCA, Demuner AJ, de Almeida RM, Fujiwara RT, Ferreira SR. Highly potent anti-leishmanial derivatives of hederagenin, a triperpenoid from Sapindus saponaria $L$. Eur J Med Chem 2016; 124: 153-159. https://doi.org/10.1016/ j.ejmech.2016.08.030

11. Jin CM, Kaewintajuk K, Jiang J, Jeong W, Kamata M, Kim HS, Wataya Y, Park H. Toxoplasma gondii: a simple high-throughput assay for drug screening in vitro. Exp parasitol 2009; 121: 132-136. https://doi.org/10.1016/j.exppara.2008.10.006
12. Giusti G, Ruggiero G, Cacciatore L. A comparative study of some spectrophotometric and colorimetric procedures for the determination of serum glutamic-oxaloacetic and glutamic-pyruvic transaminase in hepatic diseases. Enzymol Biol Clin (Basel) 1969; 10: 17-38. https://doi.org/10.1159/000458296

13. Guo HY, Jin CM, Zhang HM, Jin CM, Shen QK, Quan ZS. Synthesis and biological evaluation of (+)-usnic acid derivatives as potential anti-Toxoplasma gondii agents. J Agric Food Chem 2019; 67: 9630-9642. https://doi.org/10.1021/acs.jafc.9b02173

14. Dubey JP. History of the discovery of the life cycle of Toxoplasma gondii. Int J Parasitol 2009; 39: 877-882. https://doi.org/10.1016/ j.ijpara.2009.01.005

15. Zhang HB, Shen QK, Wang H, Jin C, Jin CM, Quan ZS. Synthesis and evaluation of novel arctigenin derivatives as potential anti-Toxoplasma gondii agents. Eur J Med Chem 2018; 158: 414-427. https://doi.org/10.1016/j.ejmech.2018.08.087

16. Gurung RB, Purbe B, Gyawali P, Risal P. The ratio of aspartate aminotransferase to alanine aminotransferase (AST/ALT): the correlation of value with underlying severity of alcoholic liver disease. Kathmandu Univ Med J (KUMJ) 2013; 11: 233-236. https:// doi.org/10.3126/kumj.v11i3.12511

17. Autier B, Dion S, Robert-Gangneux F. The liver as an organ at risk for Toxoplasma transmission during transplantation: myth or reality? J Clin Pathol 2018; 71: 763-766. https://doi.org/10.1136/ jclinpath-2018-205066

18. Dillioglugil MO, Kir HM, Demir C, Ilbay G, Sahin D, Dillioglugil O, Bambal G, Mekik H, Ates N. Effect of pentylenetetrazole and sound stimulation induced single and repeated convulsive seizures on the mda, gsh and no levels, and sod activities in rat liver and kidney tissues. Brain Res Bull 2010; 83: 356-359. https://doi.org/10.1016/j.brainresbull.2010.09.007

19. Kučera O, Endlicher R, Rychtrmoc D, Lotková H, Sobotka O, Červinková Z. Acetaminophen toxicity in rat and mouse hepatocytes in vitro. Drug Chem Toxicol 2017; 40: 448-456. https://doi. org/10.1080/01480545.2016.1255953

20. Macias-Barragan J, Caligiuri A, García-Banuelos J, Parola M, Pinzani M, Armendariz-Borunda J. Effects of alpha lipoic acid and pirfenidone on liver cells antioxidant modulation against oxidative damage. Rev Med Chil 2014; 142: 1553-1564. https:// doi.org/10.4067/S0034-98872014001200009

21. Karaman U, Celik T, Kiran TR, Colak C, Daldal NU. Malondialdehyde, glutathione, and nitric oxide levels in Toxoplasma gondii seropositive patients. Korean J Parasitol 2008; 46: 293-295. https://doi.org/10.3347/kjp.2008.46.4.293

22. Xu X, Liu T, Zhang A, Huo X, Luo Q, Chen Z, Yu L, Li Q, Liu L, Lun ZR, Shen J. Reactive oxygen species-triggered trophoblast apoptosis is initiated by endoplasmic reticulum stress via activation of caspase-12, chop, and the JNK pathway in Toxoplasma gondii infection in mice. Infect immun 2012; 80: 2121-2132. https://doi.org/10.1128/IAI.06295-11 
